\title{
Summaries of Proceedings of Human Rights Monitoring Bodies
}

(Covering the Period September 2017-August 2018)

Denise Venturi and Silvia Venier

\author{
Universal Periodic Review (UPR) $\stackrel{*}{*}$
}

Bahrain - Adoption in the plenary session A/HRC/36/2, 14June 2018 Bahrain received 175 recommendations during the UPR cycle and supported 139 of them, while only took note of the remaining 36 for being either in consistent with Islamic law or not complying with national legislation and/or requiring further study. Bahrain's Head of Delegation reaffirmed the country's commitment towards human rights and listed some major achievements in this such as the 2017 Family Law in line with CEDAw. In general, States praised Bahrain on their commitment to the UPR process and expressed appreciation for the high rate of supported recommendations. States' attention mainly focused on women's rights and advancement of the rule of law. With particular regard to the former, States underlined Bahrain's positive engagement in working towards gender equality, as reflected particularly in the country's National Plan, which is also aimed at empowering women and boosting their access to business. States encouraged Bahrain to further undertake steps in this area, for example by protecting migrant working women through the ratification of ad hoc human rights and labour conventions. NGOs and other stakeholders expressed concern at Bahrain's record on rule of law and freedom of expression, underlining the sheer number of recommendations focusing on this area and called for comprehensive reform in this regard. Notably, Bahrain's commitment to the UPR was also put into question, considering the issues and setbacks in the aforementioned areas. Criticism of Bahrain was expressed mainly with regard to crackdown on dissent and human rights defenders, also

* Denise Venturi, Faculty of Law, Catholic University of Leuven, Belgium. Member, Editorial Committee and Editorial Board, Asian Yearbook of Human Rights and Humanitarian Law (AYBHRHL).

Silvia Venier, Institute of Law, Politics and Development, Sant'Anna School of Advanced Studies, Pisa (Italy). Member, Editorial Committee and Editorial Board, Asian Yearbook of Human Rights and Humanitarian Law (АYвH RHL).

The views expressed herein are those of the authors and do not necessarily reflect the views of the United Nations. 
considered was an issue that the country had denied access to UN special procedures. Bahrain dismissed these allegations as being false and reiterated its commitment to the human rights system, as proven by the number of international instruments ratified.

\section{Indonesia - Adoption in the plenary session $\mathrm{A} / \mathrm{HRC} / 36 / 2,14 \mathrm{June}$ 2018}

Indonesia expressed appreciation for the UPR process and the vast participation and engagement it benefitted from. It also pointed out that the review in May had been the occasion to conduct a series of awareness-raising activities. In this cycle, Indonesia received 225 recommendations, 150 of which were immediately accepted and a further 17 were endorsed at a later stage, concerning in particular ratification human rights treaties, protection against discrimination, prevention of intolerance and better implementation of laws and regulations. The remaining 58 recommendations were, however, not accepted, since they were not considered in line with Indonesia's priorities in the area of human rights, such as those focused on LGBTI rights and death penalty. The delegation of Indonesia admitted the existing gaps in human rights commitment; on the one hand it noted the challenges in fulfilling economic and social rights, on the other hand it stressed the Government's efforts in pursuing inclusive policy and measures, especially for the most disadvantaged ones. States praised Indonesia for its engagement in the UPR process as well as for the steps undertaken in the ratification of human rights treaties. The latter was echoed by UN Women who commended the Country for showing support towards international instruments aimed at improving women's participation in public life; at the same time, it recommended to repeal discriminatory legislation against women and girls and take a firmer stance against Female Genital Mutilation. Another area on which States concentrated their attention was measures taken by Indonesia vis-à-vis children's rights, encouraging the Country to strengthen programmes on education and social policies and welcoming the ratification of the Optional protocols to the Convention on the Rights of the Child. As for other stakeholders, their comments related to the worrying situation of human rights in the province of Papua, as well as the necessity to guarantee freedom of expression, freedom of religion and abolish death penalty. LGBTI rights were another area in relation to which the Indonesia received concerned comments and calls for taking initiative against hate speech, violence and discrimination. 


\section{India - Adoption in the plenary session A/HRC/36/2, 14 June 2018}

India praised the UPR mechanism, underlining its peer review nature and reiterating the country's commitment toward the process. During its UPR cycle, India received 250 recommendations; $15^{2}$ of them enjoyed the Country's support, while the remaining 98 were noted. States commended India for its engagement in the recommendations received, despite the challenges it faced. States' comments focused on the efforts towards the inclusion of persons with disabilities, elderly, poor persons and other vulnerable groups, as well as on the need to put in place effective legislation to counter trafficking, sexual violence against women and girls and domestic violence. Other recommendations related to the need to take steps towards the ratification of the Convention against Torture as well as to strengthen national human rights mechanisms. Stakeholders other than States provided comments to India in relation to child marriage and violence against women. Other areas of concern were represented by intolerance and discrimination against religious minorities and vulnerable parts of the population as well as by cast discrimination, especially against Dalits.

\section{The Philippines - Adoption in the plenary session A/HRC/36/2, 14 June 2018}

The Philippines stated that the UPR mechanism had proven useful in encouraging the country to continue with ongoing efforts in the fulfilment of human rights. The State received 257 recommendations and 103 were fully accepted and supported. Those were mainly related to strengthening the protection of vulnerable groups, the protection of family, access to health care and education as well as mitigation of adverse climate change effects. More then a half of the remaining recommendations - mainly those requiring legislative changes - were in principle accepted by the country, which noted, at the same time, that it could not guarantee their full implementation within the current UPR cycle. Recommendations related to extrajudicial killings allegedly occurred during the Government's anti-illegal drug campaign were only noted. The Philippines reiterated that these deaths could not be considered extrajudicial killings but arose from legitimate law enforcement operations. Other countries commended the Philippines on various issues, such as the adoption of a national development plan and the commitment to human rights mechanisms, notwithstanding the natural disasters which had affected the country in recent years. Several countries were worried about the number of deaths occurred in 
the fight against illegal drugs and encouraged the State under review to comply with human rights and international standards in this field of operation. The anti-illegal drug campaign represented also a great concern for other stakeholders, who called for a comprehensive and sustainable response to drug problem in the country.

\section{Republic of Korea - Adoption in the plenary session A/HRC/37/2, 14 June 2018}

The government of the Republic of Korea reiterated its support to the UPR mechanism, through which it received 218 recommendations and supported 121 of them. The Republic of Korea specified that it could not support some recommendations as they required further examination, such as the measures to combat discrimination and to facilitate the participation of women in the public life. The delegation further reiterated its commitment to human rights, as emerging from the national plan for the promotion and protection of human rights, to be carried out through extensive consultations with civil society. Several States' recommendations focused on the Republic of Korea's commitment towards the implementation of international human rights treaties, such as the International Convention on the Protection of the Rights of All Migrant Workers and Members of Their Families. Other recommendations concerned the country's actions in relation to combating hate speech, for which encouraged the Republic of Korea to continue and strengthen its effort in this regard. Other stakeholders expressed concerns regarding objection to military service but, at the same time, they expressed appreciation for the Country's willingness to the issue.

$$
\text { Japan - Adoption in the plenary session A/H RC/37/2, 14 June } 2018
$$

At the outsets, the Japanese delegation expressed its full commitment to the UPR mechanism and to the review of the recommendations received. The latter were a total number of 217 , of which 145 enjoyed the country's support. Japan emphasized the importance of making the UPR process more effective and of raising awareness on the results of the review. Several countries commended Japan's efforts in scaling up the protection of migrant workers' rights, as well as of promoting the participation and the advancement of women in the workplace. In order to achieve these results, Japan was encouraged to consider ratifying the International Convention on the Protection of the Rights of 
All Migrant Workers and Members of Their Families. Other stakeholders concentrated their attention on the absence of an anti-discrimination legal framework and encouraged Japan to put a remedy to such circumstance. Moreover, Japan was called to establish an official moratorium on executions, as a first step towards the abolition of death penalty.

\section{Sri Lanka - Adoption in the plenary session A/HRC/37/2, 14 June 2018}

Sri Lanka received 230 recommendations, 177 of which were accepted and 53 noted. The Country stated that the delegation participated to the review in the backdrop of a transformed setting, following 2015 elections and with a renewed focus on human rights. In this context, the Country acceded to the Optional Protocol to the Convention against Torture, ratified the Convention on the Rights of Persons with Disabilities and adopted provisions aimed at criminalizing enforced disappearance as well as at countering terrorism while respecting international standards. Sri Lanka also expressed appreciation for OHCHR assistance with the UPR reporting process. During the UPR review, the Country received appreciation for its efforts towards reconciliation, rule of law, protection of victims of crimes, freedom of expression and combating hate speech. It was encouraged to take further steps in providing equal access to sexual and reproductive health services, tackling sexual and gender-based violence, as well as to support young people and populations in disadvantage. Several States welcomed Sri Lanka's National Human Rights Action Plan and underlined the Country's commitment towards the eradication of poverty. At the same time, they expressed the hope for Sri Lanka's continuous efforts in promoting sustainability. Other stakeholders voiced their concerns over sand mining and dumping activities which risked endangering the environment and the life of communities. Concern was also expressed with regard to attacks against religious minorities, such as Christians and Muslims. Moreover, calls for enhancing accountability especially regarding enforced disappearances were reiterated.

\section{United Arab Emirates - Adoption in the plenary session $\mathrm{A} /$ H RC/38/2, 24 August 2018}

The United Arab Emirates (UAE) received 232 recommendations and accepted 132 of them. The delegation of the UAE highlighted that the Standing 
Committee to follow up the UPR studied the recommendations carefully and informed that a large number of recommendations had been already implemented. For the remaining ones, UAE committed to implement them within the next UPR cycle. The majority of accepted recommendations focused on a variety of issues, such as cooperation with the United Nations Treaty Bodies and Special Mechanisms, combating human trafficking and work exploitation, promoting and ensuring gender equality and protecting persons with disabilities. States generally commended UAE for accepting a large number of recommendations and recognized the Country's efforts taken in various areas, such as combating trafficking, work exploitations and non-discrimination. States called on UAE to enhance freedom of expression and continue taking steps to protect women and children. Some States expressed preoccupation for UAE's treatment of political dissidents, arbitrary confinement and detention. As for other stakeholders' comments, several of them started out by expressing appreciation for UAE's commitment to the UN mechanisms, especially the UPR. At the same time, various comments concerned to the need for UAE to step up its commitment in ensuring gender equality and women's rights, as well as to stop torture and other ill-treatment, especially of human rights defenders.

\section{Turkmenistan - Report of the Working Group on the Universal Periodic Review A/HRC/39/3, 6 July 2018}

The delegation of Turkmenistan highlighted that, during the reporting period, it had engaged in a dialogue with the Committee on the Rights of Persons with Disabilities, the Committee on the Elimination of Racial Discrimination, the Human Rights Committee and the Committee against Torture. It also underlined the Country's efforts in bringing its legislation in line with human rights standards, in light also the 2016 new Constitution that had also introduced the Commissioner for Human Rights. States commended Turkmenistan for the adoption of the National Action Plan for Gender Equality and the one for Human Rights, for its efforts in combating trafficking, discrimination and for its engagement in ratifying human rights instruments and setting up a national Ombudsperson in the new Constitution. Other States, although commending Turkmenistan for its efforts in promoting human rights, noted with concern the situation regarding enforced disappearance, torture, incommunicado detentions, use of excessive force by security forces and restrictions of movements and expressions. Some States, in particular, remained deeply concerned that Turkmenistan's situation had not adequately improved since the 
last UPR cycle. Before the adoption of the report in the plenary session, Turkmenistan had received and supported 116 recommendations.

\section{Uzbekistan - Report of the Working Group on the Universal Periodic Review A/HRC/39/7, 9 July 2018}

In its presentation, the delegation of Uzbekistan stated that the Country had published its first ever parliamentary report on the situation of human rights. Moreover, it also informed that judicial reform was taking place, aimed at ensuring an independent judiciary system through a constitutional reform. Uzbekistan undertook also efforts in tackling corruption, for example by adopting a new law aimed at ensuring transparency. In this context, the Country established the Office of the Business Ombudsperson in 2017, an independent body mandated at protection the rights of entrepreneurs and entrepreneurship, providing legal support and guaranteeing freedom of entrepreneurship. States welcomed Uzbekistan's progresses in the field of human rights but, at they same time, they noted some shortcomings, particularly the gap between the Country's international human rights obligations and their actual implementation. Several countries expressed their hope that Uzbekistan would continue tackling harassment against civil society and encouraged the Country under review to strengthen the protection of women (especially victims of trafficking), children, migrants and persons with disabilities. Before the adoption of the report in the plenary session, Uzbekistan had received and supported 116 recommendations.

\section{Bangladesh - Report of the Working Group on the Universal Periodic Review A/HRC/39/12, 11 July 2018}

The delegation of Bangladesh noted with regret that discrimination and human rights violations were still taking place nowadays and underlined the Country's efforts towards Rohingya refugees fleeing Myanmar. It also pointed out the progress done in terms of socioeconomic development and in reducing poverty. As for support to international human rights the delegation stated that, before entering into any further international obligations, the Country needed to address capacity-building issues regarding its national institutions. During the review, many States congratulated Bangladesh for hosting Rohingya refugees, as well as for taking steps towards the improvement of its human rights record, notwithstanding several challenges. Other States 
expressed appreciation for Bangladesh's commitment to the UPR process and for having implemented some of the previous recommendations. At the same time, concerns were expressed with regard to limitations of freedom of association and expression, enforced disappearances, extrajudicial killings. Before the adoption of the report in the plenary session, 167 recommendations enjoyed the support of Bangladesh, while 24 were supported but implemented at a later stage. Furthermore, 6o recommendations were only noted as they did not enjoy the Country's support.

\section{Azerbaijan - Report of the Working Group on the Universal Periodic Review A/HRC/39/14, 11 July 2018}

Azerbaijan reiterated its commitment to the UPR process, as highlighted by the fact that it was among those States that had fulfilled their reporting duties in a timely manner. In 2016, the Constitution was amended with the aim to strengthening the protection human rights and fundamental freedoms. Azerbaijan referred that it undertook measures aimed at supporting the development of the legal profession, fighting corruption and sustaining socioeconomic development. Disagreement emerged between the State under review and Armenia with regard to contested territories. States commended Azerbaijan's progresses in the fields of education, fight against corruption and health care. However, States also expressed concerns regarding torture, intimidations and ill-treatments against journalists and human rights defenders. Similarly, preoccupation was also expressed in relation to measures restricting the independence of lawyers. Before the adoption of the report in the plenary session, Azerbaijan had received and supported 152 recommendations, while further 101 were put aside for a more in-depth examination. Finally, the Country did not support 6 recommendations, all made by Armenia, as it deemed them not related to the UPR process.

\section{Human Rights Committee (H Rctee)}

\section{Concluding Observation on the fifth periodic report of Jordan (cCPR/c/JOR/cO/5, 4 December 2017)}

The HRCtee welcomed the positive legislative measures taken by Jordan, including the amendments to the Constitution in 2011 and the establishment of the Constitutional Court in 2012, as well as the appointment of a Human Rights Coordinator in 2014 and the adoption a Human Rights action plan covering the 
2016-2025 period. Nevertheless, it expressed concern over the lack of an express recognition of the primacy of the Covenant over sharia law in the Constitution and the lack of an independent judiciary. the lack of a comprehensive anti-discrimination legislation particularly with regards to women and called the State Party to strengthen the legal framework for the protection of women against domestic violence. Major matters of concern were also related to the broadening of the definition of terrorism in counter-terrorism legislation, the low threshold for applying the death penalty, shortcomings in the legislation on the prohibition of torture and on the voluntary termination of pregnancy. The HRctee finally reiterated its concern for the lack of adequate protection granted to migrant workers and refugees and the restrictions to fundamental liberties, such as freedom of religion, of expression and of association.

\section{Concluding Observation on the sixth periodic report of Australia (cCPR/c/AUS/co/6, 1 December 2017)}

The HRCtee welcomed some positive developments in the State party's legislation relevant to human rights protection, including the adoption of a Human Rights Act in 2011 and the establishment of a standing national human rights mechanism. Some matters of concern were however pointed out with reference to the actual implementation of the Covenant rights. These for instance, the lack of legitimacy, necessity and proportionality of some counter-terrorism measures, the lack of direct protection against discrimination on the basis of religion at the federal level, the inadequate efforts to protect women against domestic violence, the practice of involuntary non-therapeutic sterilization of women and girls with intellectual disabilities and/or cognitive impairments, the lack of adequate protection against non-refoulement. In relation to this last issue, the Committee expressed concern over the rigid mandatory detention scheme under the Migration Act 1958 and over the harsh conditions of the offshore immigration processing facilities in Papua New Guinea (Manus Island), over which Australia exercises effective control and jurisdiction. The Committee finally pointed out the need to strengthen protection of indigenous peoples' rights, in particular with regards to land rights and the lack of a compensation mechanisms in certain areas, as well as with reference to the overrepresentations of indigenous Australians in prisons and the lack of access to culturally appropriate legal assistance services, including interpretation and translation services, for marginalized and disadvantaged people. 


\section{Concluding Observation on the third periodic report of Lebanon (cCPR/c/LBN/CO/3, 9 May 2018)}

The HRCtee noted favourably some legislative and policy measures taken by Lebanon, such as the adoption of the National Human Rights Action Plan covering the 2014-2019 period, the establishment of the Ministry of Human Rights and the Ministry of Women's Affairs, and the adoption of the access to information Act in 2017. Concerns were expressed over a set of issues, including the broad scope of the legislation on the state of emergency, the lack of a comprehensive anti-discriminatory legislation covering all grounds prohibited under the Covenant, the persistence of patriarchal stereotypes and domestic violence against women and the practice of unsafe abortion, the prosecution of lesbian, gay, bisexual, transgender and intersex individuals, as well as the unresolved cases of enforced disappearances and of torture and ill-treatment. Some recommendations are provided to amend national legislation on these issues and to ensure its adequate application. The HRctee also raised concerns on the arbitrary interference with the privacy of individuals including through mass surveillance and the inadequate protection of biometric data under the current legal framework. The last point mentioned by the Committee related to the condition of prisons and the treatment of prisoners, the political pressure reportedly exerted on the judiciary, the broad jurisdiction of military courts that extends to civilians, including children. Finally, the Committee acknowledged the significant contribution of the State party in hosting a large number of asylum seekers and refugees and its continuing engagement in providing assistance and protection to them, while expressing some concern in relation to the strict border admission regulations in place since January 2015 and the actual application of the non-refoulment principle.

\section{Concluding Observation on the initial report of Lao People's \\ Democratic Republic (cCPR/C/LAO/CO/1, 26July 2018)}

The HRCtee appreciated the legislative and policy measures recently adopted by the State party, such as the inclusion of a chapter on fundamental rights in the amended Constitution of 2015 and the adoption of the National Action Plan on the Prevention and Elimination of Violence against Women and Children (2014-2020), as well as the ratification of key international instruments, such as the Convention against Torture and the Convention on the Rights of Persons with Disabilities. The major matters of concern the existing regulations on the state of emergency and the overbroad definition of terrorism, the inadequate anti-discrimination framework, the prescription of the death penalty for drug-related crimes, the lack of an adequate legal framework to criminalise acts of enforced disappearances, the criminalisation of 
abortion, the inadequate measures to protect against torture and the reports on arbitrary arrest and detention, and the effective independence of the judiciary. The HRctee also noted with concern the limitations of fundamental freedoms, such as freedom of religion, of expression and of association, as well as the inadequate steps taken to protect minorities.

\section{Committee on the Convention against Torture (CAT)}

\section{Concluding Observations on the initial report of Timor-Leste (Doc. No $\mathrm{CAT} / \mathrm{C} / \mathrm{TLS} / \mathrm{co} / 1,15$ December 2017)}

The CAT welcomed the ratification of key international human rights treaties by the State party, as well as the adoption of national legislation, including on witness protection and against domestic violence, and the initiatives to protect children's rights and to provide for a platform on prisons monitoring. With reference to the principal subjects of concern, the CAT referred to the absence of any concerted efforts to bring to justice those responsible for the gross human rights violations committed during the Indonesian occupation and the postreferendum period, including with reference to the little progress in investigating enforced disappearances and the impunity for acts of torture and ill-treatment. The excessive use of force by the police and the cases of torture and ill-treatment currently a matter of major concern, as the lack of information provided on the measures and procedures in place to ensure the practical application of fundamental legal safeguards to prevent torture and ill-treatment. The CAT also regretted that the State party has provided information on specific measures taken by prison authorities or prosecutors in response to recommendations made by other public bodies, such as the Ministry of Health and Human Rights Ombudsman Office, following the inspections of detention centres. Finally the Committee noted the limited availability of psychiatric services for persons with mental disabilities, the discrimination based on sexual orientation, the lack of explicit prohibition of corporal punishment and the cases of domestic violence.

\section{Concluding Observations on the third periodic report of Qatar}

(Doc. No $C A T / C / Q A T / c o / 3$, 4 June 2018)

The CAT commended the State party's recent initiatives to amend its policies and procedures in order to afford greater protection of human rights, including the decision to accede to international human rights treaties, the establishment of the national committee for combating human trafficking, and the adoption of national development strategies. It remained concerned, however, 
that there is no clear provision in the State party's legislation to ensure that the prohibition of torture is absolute and non-derogable and no explicit provisions are made on the right to request and receive a medical examination promptly upon deprivation of liberty. Additional matters of concern raised by the CAT included the counter-terrorism legislation, the lack of an independent judiciary and the absence of information on investigations on cases of torture and ill-treatment, as well as on the impacts of training programmes devoted to prohibition of torture and of measures taken to protection human rights defenders and journalists. It finally raised some serious concerns in relation to the respect of the principle of non-refoulment, the protection of migrant workers and the detention of asylum seekers, as well as cases of human trafficking.

\section{Concluding Observations on the third periodic report of Tajikistan} (Doc. No $C A T / C / T J K / C O / 3,18 J u n e ~ 2018$ )

The CAT welcomed the State party's ratification of international instruments, such as the Optional Protocol to the Convention on the Elimination of All Forms of Discrimination against Women and the Convention on the Prevention and Punishment of the Crime of Genocide, as well as the initiatives to revise its legislation in areas of relevance to the Convention against Torture, including the adoption of the Prevention of Domestic Violence Act, the Act on Combating Trafficking in Persons and the Provision of Services for Human Trafficking Victims, the revised Law on Refugees, and the Children's Rights Act. It expressed concern, however, about allegations that torture and ill-treatment continue to be routinely practised by law enforcement officials in the State party, about the low percentage of complaints of torture and ill-treatment that have been made the subject of criminal investigations, and about the fact that the Criminal Code continues to provide for inappropriately low penalties for torture. Matters of concern to the lack of appropriate legal safeguards from the very outset of the deprivation of liberty and the dramatic drop in the number of lawyers in the country that may affect the right to a prompt access to an independent lawyer, as well as to the lack of fair and adequate compensation to victims of torture. The Committee noted with concern the cases of retaliation against lawyers and human rights defenders, the several instances of death in custody and the lack of adequate monitoring of prisons and detention centres. Finally, recommendations were provided to ensure an adequate level of protection of vulnerable groups, including children, women, sexual minorities and refugees. 


\section{Committee on the Elimination of Discrimination against Women (CEDAW)}

\section{Concluding Observations on the sixth periodic report of Israel (Doc. No CEDAW/C/ISR/co/6, 17 November 2017)}

The CEDAW welcomed the progress achieved in undertaking legislative reforms, including the amendments to the marriage age law, the employment of women law, the prevention of sexual harassment regulations and the religious judges law, as well as the initiatives taken by the State party to improve its policies and institutional framework aimed at accelerating the elimination of discrimination against women. The principal areas of concern highlighted by the CEDAW included covering both direct and indirect discrimination, the limitations to women's freedom of movement and the cases of domestic violence and sexual harassment, the inadequate protection of women pertaining to vulnerable categories, the position maintained by the State party on the non-applicability of the Convention to the Occupied Palestinian Territories, and the lack of family reunification provisions applicable to the inhabitants of the Gaza strip. The CEDAW expressed its concern for the fact that Israel remains a destination country for trafficking in women and girls for purposes of sexual and labour exploitation, also noting the low rate of prosecution of traffickers owing to the lack of coordination between the police and the migration services. As per women's participation in the political and public life, the Committee noted the low number of women in the parliament and ministerial, senior academic and diplomatic positions and the fact that women cannot serve as judges in rabbinical courts. In many of the issues touched upon by the Committee, including participation in political life, employment, education and health, it emerged the particularly disadvantaged position of Israeli-Arab and Bedouin women.

\section{Concluding Observations on on the fifth periodic report of Singapore (Doc No CEDAW/c/sGP/co/5, 21 November 2017)}

The CEDAW expressed appreciation for important legislative developments taken by the State Party, including the Women's Charter (Amendment) Act in 2016, the Protection from Harassment Act in 2014, the Prevention of Human Trafficking Act in 2014, the Employment, Parental Leave and Other Measures Act in 2013, as well as the ratification of international instruments, including the Protocol to Prevent, Suppress and Punish Trafficking in Persons, Especially Women and Children, supplementing the United Nations Convention against Transnational Organized Crime and the Convention on the Rights of Persons with Disabilities. The Committee welcomed the initiatives taken to promote 
gender equality and protect the rights of women, but reiterated its concern about the still inadequate legal framework, considering inter alia the absence of a specific definition of discrimination against women in the State party's legislation. The Committee remained concerned about the persistence of discriminatory stereotypes about the role of women as primary caregivers, the lack of statistical data and of underreporting of cases of gender-based violence against women, the lack of access to sufficient measures of support and protection on the part of victims of human trafficking, the underrepresentation of women in political and public life and in corporate boards and the inadequate protection provided to the most vulnerable and disadvantaged women.

Concluding Observations on the combined second and third periodic reports of Oman (Doc. No CEDAW/C/OMN/CO/2-3, 22 November 2017)

THE CEDAW WELCOMED THE progress achieved in undertaking legislative reforms by the State party, such as the adoption of the Child Law in 2014, the Royal Decree No. 78/2013 providing for the principle of equal pay for work of equal value in the civil service, the Civil Transactions Law in 2013, and the effort to improve its institutional and policy framework aimed at accelerating the elimination of discrimination against women and promoting gender equality, including the adoption of the Social action strategy (which focuses on changing gender stereotypes and providing an environment that affirms the pivotal economic role of women in the family and in society and the participation of women in decision-making positions), the national agricultural development strategy (which prioritizes the establishment of non-governmental agricultural organizations for rural women with a view to promoting their economic empowerment), the establishment of the Family Protection Department (which formulates protection plans and receives complaints about gender-based violence against women). The Committee also welcomed the ratification of Oman of the Arab Convention against Transnational Organized Crime and the United Nations Convention against Corruption. Nevertheless, some matters of concern were pointed out, including the persistence of discriminatory provisions in the State party's legislation, in particular the Penal Code, the discriminatory stereotypes on the role of women within the law and the society of Oman, women's limited knowledge of their access to justice rights and existing complaint mechanisms and language barriers, the fact that women human rights defenders and their relatives have allegedly been subjected to various forms of harassment, violence and intimidation, the lack of documentation and statistical data on domestic violence and the low prosecution and conviction rates and the lenient penalties imposed on perpetrators of gender-based violence against women. Additional of concern referred to 
human trafficking and exploitation of prostitution, the inadequate participation of women in public life, inadequate efforts to ensure non-discriminatory education, employment and access to health care, and to ensure protection of the most vulnerable groups of women.

\section{Concluding Observations on the combined initial and second periodic reports of Nauru (Doc. NO CEDAW/C/NRU/CO/1-2, 22 November 2017)}

The CEDAW welcomed some positive developments in legislative reforms underaking by Nauru, including the adoption of the Domestic Violence and Family Protection Act in 2017, the Crimes Act in 2016 which broadened the definition of rape, the Adoption of Children (Amendment) Act in 2015, the Education Act in 2011, as well as the efforts to improve the institutional and policy framework, including with the adoption of the national policy on disability, the national women's policy, the Young women's action plan (2009-2015), the National sustainable development strategy (2005-2025), recognizing the rights of women, promoting equal opportunities and expressing a commitment to integrating gender across all sectors, and the Gender country plan, providing support for women and girls affected by domestic violence, alcohol and teenage pregnancy. The Committee also welcomed the ratification of the Convention against Torture and the Convention on the Rights of Persons with Disabilities. The CEDAW expressed concern over the absence of a comprehensive definition of discrimination against women in the legislative framework, the lack of adequate mechanisms to ensure access to justice, the prevalence of social and cultural stereotypes on the role of women in society, the underreporting of cases of domestic violence and the lack of systematic data collection, the limited efforts to address trafficking in persons and exploitation of prostitution, the underrepresentation of women in political life and the inadequate measures to ensure access to education and to health care. The CEDAW also noted the environmental challenges faced by the State party and remained concerned about the negative consequences of long-term phosphate mining for the health of women and for the lack of attention on the specific impacts on women of climate change.

\section{Concluding Observations on the combined second to fourth periodic reports of the Democratic People's Republic of Korea}

(Doc. No CEDAW/c/PRK/CO/2-4, 22 November 2017)

The CEDAW expressed appreciation for important legislative developments taken by the State Party, including the adoption in 2010 of the Law on the Protection and Promotion of the Rights of Women, the Law on the Protection and 
Promotion of the Rights of Children and the Law on Labour Protection, and welcomed the efforts to improve its institutional and policy framework, including with the establishment of a national committee for implementing international human rights treaties in 2015, and the ratification of the Convention on the Rights of Persons with Disabilities and of the Optional Protocol to the Convention on the Rights of the Child on the sale of children, child prostitution and child pornography. The CEDAw noted that the economic sanctions imposed by the international community as a consequence of the State party's policies have a disproportionate impact on women and invited the State to address all recommendations as a matter of high priority. It regretted that the State's party laws are not publicly available to allow for independent monitoring and expressed concerned about the lack of an independent complaint mechanism for women's human rights violations and women's non-awareness of their rights, the absence of autonomous women's human rights organizations, the prevalence of social and cultural stereotypes on the role of women in society, the lack of adequate protection of women against domestic violence and the fact that marital rape is not criminalised, the absence of legal provisions that criminalize trafficking in persons and of measures to identify and protect women who are victims, the extremely weak representation of women in high level posts, the lack of adequate access to education and health care.

\section{Concluding Observations on the fifth periodic report of Kuwait (Doc. No CEDAW/C/KWT/cO/5, 22 November 2017)}

The CEDAW welcomed some positive developments in the adoption of new legislation, including the acts on domestic workers, on trafficking in persons, in particular women and girls, on the establishment of a national human rights institution (the Human Rights Diwan) and on the protection of national unity, which criminalizes incitement to discrimination against women. It also expressed appreciations to the State party's efforts to improve its institutional and policy framework, including the extension of the mandate of the Protection of Public Morals and Anti-Trafficking Department under the Ministry of the Interior to cases relating to sexual exploitation, bondage and bondage-like practices, the inclusion of gender-specific goals and indicators in the national development plan covering the period 2015-2020, the achievement of gender equality in all stages of education (with its first place ranking globally in terms of closing the gender gap with respect to access to education), the progress in improving health-care services for women and children and the decrease in infant, maternal and child mortality rates and the establishment of a housing fund to support certain groups of women (widows, divorcees, unmarried women and women married to non-Kuwaiti citizens). The CEDAW nevertheless 
reiterated the concern over the absence of a definition of direct and indirect discrimination against women and over the fact that the access to justice is hindered by discriminatory laws on marriage and family relations and employment, the legalization of harmful practices, the non-criminalization of numerous forms of gender-based violence against women and the application of discriminatory judicial proceedings in this regard. It also noted the low participation of women in leadership positions, and remained particular of inadequate measures to protect the disadvantaged groups of women, including refugee, migrant, Stateless bedouin, Shia, Baha'i and other non-Muslim women and girls, Kuwaiti women married to non-Kuwaiti men and women and girls with disabilities.

\section{Concluding Observations on the combined initial to third periodic reports of the Marshall Islands (Doc. No CEDAW/C/MHL/CO/1-3, 14 March 2018)}

The CEDAW expressed appreciation for important legislative developments taken by the State Party, including the Prohibition of Trafficking in Persons Act in 2017, the Births, Deaths and Marriage Registration (Amendment) Act in 2016, the Amendment to the Criminal Code, by which the provisions on sexual assault were revised, in 2013, and the Domestic Violence Prevention and Protection Act, in 2011, as well as for some positive policy and institutional developments. The Committee noted that the effects of the nuclear testing programme conducted by the United States of America from 1946 to $195^{8}$ continue to pose severe environmental and health problems in the State party, especially to Marshallese women and girls who disproportionately suffer from thyroid and other cancers as well as other reproductive health problems. The CEDAW also expressed concern over the lack of a comprehensive definition of discrimination and the lack of incorporation of some provisions of the Convention into the national legislative instruments. The entrenched patriarchal attitudes and the persistence of discriminatory stereotypes concerning the roles and responsibilities of women and men were also recognised, as were the high prevalence of gender-based violence against women which remains culturally accepted and underreported. Additional matters of concern referred to the underrepresentation of women in political and public life, and the inadequate measures to ensure access to education, employment and healthcare, and the lack of special protection mechanisms available to the most disadvantaged groups of women. 


\section{Concluding Observations on the combined third to fifth periodic reports of Malaysia (Doc. NO CEDAW/C/MYS/CO/3-5, 14 March 2018)}

The CEDAW welcomed some positive developments in undertaking legislative reforms, including the amendments to the Penal Code to increase the penalties for offences relating to rape and incest, the Anti-Trafficking in Persons and Anti-Smuggling of Migrants Act further amended in 2015, the Amendments to the Domestic Violence Act of 1994 to widen the definition of domestic violence to include emotional, mental and psychological forms of violence and to improve protection for survivors of abuse, the amendments to the Employment Act to prohibit sexual harassment in the workplace and to extend maternity leave benefits to all women employees, as well as the initiatives taken at the policy level and the ratification of international human rights treaties such as the Convention on the rights of Persons with disabilities. It reiterated however the concern that the Convention on the Elimination of all Forms of Discrimination against Women is not yet part of the national legal system, and the legal system as such does not provide for a comprehensive definition of discrimination. The Committee remained concerned about the existence of multiple barriers impeding women's and girls' access to justice and effective remedies for violations of their rights, including discriminatory stereotypes and gender biases among personnel throughout the justice system. Deep concern was expressed for the issuance of a fatwa by the Malaysian National Council of Islamic Religious Affairs in April 2009, which made it obligatory for Muslim women to undergo female genital circumcision (female genital mutilation). With reference to domestic violence, the Committee complained about the lack of legislation criminalising marital rape and the lack of data available on the cases reported and the investigations carried out. Additional areas of concern included the obstacles faced by certain groups of women to access education, health care and employment, and the weak participation to public life.

\section{Concluding Observations on the eighth periodic report of the \\ Republic of Korea (Doc No CE DAW/C/KOR/CO/8, 14 March 2018)}

The CEDAW expressed appreciation for important legislative developments taken by the State Party, including the Multicultural Families Support Act designed to aid migrant women in creating social support networks, the Framework Act on Gender Equality, the Act on the Prevention of Sexual Assault and Protection of Victims, the Equal Employment Opportunity and Work-Family Balance Assistance Act, the Act on the Prevention of Sexual Trafficking and Protection of Victims, the Act on the Prevention of Domestic Violence. The efforts to improve the institutional and policy framework aimed at accelerating the elimination of discrimination against women and promoting gender 
equality were also recognised, as were the ratification of international instruments. The Committee however noted with concern that the State party has yet to adopt a comprehensive anti-discrimination law and that women are not fully aware of their rights, while cases of domestic violence, sexual violence online and sexual harassment in the workplace are increasing and are not accompanied by appropriate levels of investigation and punishment. Additional areas of concern included the absence of a comprehensive law on trafficking in women and girls, the entrenched gender-discriminatory stereotypes in schools and in the health system and the persistence of gender gap in salaries.

\section{Concluding Observations on the combined third and fourth periodic reports of Saudi Arabia (Doc No CEDAW/c/sAU/co/3-4, 14 March 2018)}

The CEDAW expressed appreciation for important legislative developments recently taken by the State Party, including the Supreme Orders in 2017, which allows the issuance of driving licences on equal terms to women and men and which establish that all government entities shall refrain from requiring a woman to obtain a male guardian's permission in order to have access to services and procedures, and the Law on Protection from Abuse which criminalizes domestic violence, including physical, psychological and sexual violence. It also welcomed the State party's efforts to improve its institutional and policy framework and the ratification of international instruments. The CEDAW expressed its concern for the absence of a comprehensive anti-discrimination legislation and the persistence of discriminatory laws in the State party which subjects women's enjoyment of most of their rights under the Convention to the authorization of a male guardian. The Committee was also concerned about credible and consistent information that Saudi Arabia, through its military operations in Yemen, is responsible for violations of the rights of Yemeni women and girls. It reiterated the concern for the existence of barriers to women's access to justice, to education, to adequate health care, the lack of a vibrant and diversified civil society, the persistence of discriminatory stereotypes and of domestic violence and sexual harassment, and the non-criminalisation of such conduct and the lack of adequate mechanisms to ensure protection of victims. Further areas of concern included the very low participation of women in public and political life, and the inadequate efforts to protect the most disadvantaged groups of women. 


\section{Concluding Observations on the eighth periodic report of Australia (Doc. No CEDAW/C/AUS/co/8, 2oJuly 2018)}

The CEDAW expressed appreciation for important legislative developments taken by the State Party, including the Amendments to the Marriage Act, guaranteeing the right for all couples to marry, regardless of their gender, the amendments to criminal legislation and to the Sex Discrimination Act, the Workplace Gender Equality Act, the Paid Parental Leave Amendment Act and the amendment to the Family Law Act, introducing a definition of family violence that includes physical, emotional and economic abuse. It also welcomed the improvement of the policy and institutional frameworks, which include the National Action Plan on Women, Peace and Security (2012-2018) and the National Plan to Reduce Violence against Women and their Children (20102022). The Committee noted with concern the absence of a constitutional recognition of equality between men and women and the lack of harmonisation of anti-discriminatory legislation, and recommended the State party to ensure that the Office for Women has a strong mandate and sufficient resources. It also expressed concern about harmful practices such as forced marriages and non-consensual administration of contraceptives and abortions and sterilisation of women with disabilities. Additional areas for further attention included the gendered social and environmental impact of the State party's extractive industry projects and the lack of a human rights perspective on climate change taking into consideration the most vulnerable women. Finally, the CEDAW mentioned the need to improve protection against human trafficking, to ensure wider participation of women in public and political life, and to strengthen the collection of data on women's access to education, employment and healthcare, taking into consideration the special needs of the most vulnerable groups of women.

\section{Concluding Observations on the fifth periodic report of Turkmenistan (Doc. No CEDAW/C/TKM/co/5, 2o July 2018)}

The CEDAW welcomed the positive recent developments in the legislation of the State party, including the adoption of the Employment Act, providing for equal rights and opportunities of women and men in employment, legal protection against discrimination in the workplace and unemployment benefits, the Civil Service Act, guaranteeing equal rights of women and men to enter into public service, the Law on the State Guarantees for the Equal Rights and Equal Opportunities of Men and Women, guaranteeing gender equality and prohibiting discrimination on the basis of sex, the revised Education Act, guaranteeing equal access of girls and boys to free and compulsory education, the revised Military Duty and Military Service Act of Turkmenistan, allowing 
women to participate in military training. The CEDAW expressed some concern in relation to the lack of an adequate definition of discrimination against women and of harmonisation of anti-discrimination provisions, as well as with reference to the absence of a consolidated national machinery to ensure full respect and fulfilment of women's rights. The Committee was also concerned about the lack of clear indicators and data in order to measure the actual impact of its awareness-raising policies. The systemic impunity for perpetrators of gender-based violence against women and the inadequate support services to victims were also recognised. Additional areas of concern were the limited measures to implement anti-trafficking legislation, the low level of participation of women in public life, the absence of independent women's human rights organisations, the limitations in access to education, health care (particularly with reference to women and girls with HIV/AIDS) and employment, as well as the inadequate protection of women pertaining to vulnerable groups.

\section{Concluding Observations on the initial report of the State of \\ Palestine (Doc. NNO CEDAW/c/PSE/CO/1, 20July 2018)}

The CEDAW expressed appreciation for important legislative developments taken by the State Party, including the Decree Law on Juvenile Justice and the 2004 Child Law and subsequent amendments; the State party's efforts to improve its institutional and policy frameworks, including the adoption of the Cross-Sectoral National Gender Strategy (2017-2022), the Strategic Plan for Combating Violence against Women (2011-2019), the establishment of a Special Prosecutor's Office to combat gender-based violence against women and girls; as well as the accession to international instruments, such as the International Covenant on Economic, Social and Cultural Rights, the International Covenant on Civil and Political Rights, the Convention on the Rights of the Child and its Optional Protocol on the Involvement of Children in armed conflict, the International Convention on the Elimination of All Forms of Racial Discrimination, the Convention against Torture, the Convention on the Rights of People with Disabilities, the Convention against Transnational Organized Crime. The Committee noted with concern that, due to the political and geographic fragmentation of the State party's territory, women and girls continue to be subjected to different legal systems that greatly impede the full realisation of their rights under the Convention including their political and economic empowerment. It remained concerned about the absence of a definition of discrimination against women in the national legislative framework, the underrepresentation of women in conflict prevention and peace building activities, the persistence of discriminatory stereotypes concerning the roles and responsibilities of 
women and men in the family and in society, which perpetuate the subordination of women, the high prevalence of gender-based violence against women, particularly so-called honour killings, domestic and sexual violence, which remain socially accepted and underreported due to stigma suffered by victims. The CEDAW lamented the lack of data on women and girls subject to human trafficking and sexual exploitation, and was concerned of the inadequate measures taken to ensure access to education, to employment and to healthcare, especially for the most marginalised groups of women.

\section{Concluding Observations on the eighth periodic report of $\mathrm{New}$ Zealand (Doc. NO CEDAW/C/NZL/CO/8, 2oJuly 2018)}

The CEDAW welcomed some positive developments in the State party's legislation, including the Harmful Digital Communications Act, which aims at preventing and mitigating harm caused to women by digital communications and provide victims of harmful digital communications with means of redress, and in institutional and policy reforms aimed at accelerating the elimination of discrimination against women and promoting gender equality, including the National Pasifika Disability Plan (Faiva Ora) 2014-2016, which ensures Pasifika women and girls with disabilities and their family members are provided with enhanced effective support, the Marriage (Definition of Marriage) Amendment Act 2013, which allows same-sex couples to legally marry, the Māori Education Strategy, Ka Hikitia: Accelerating Success 2013-2017, which aims at achieving equity and excellence in education for Māori, the launching of a new Integrated Safety Response (ISR), which aims at ensuring immediate safety for women and children victims of domestic violence. The CEDAW noted that the Convention is however not given the necessary visibility within the State party and expressed concern in relation to the fact that legislations adopted are generally gender-neutral, which may result in loss of the specificity of gender based discrimination and in an inadequate protection of women against direct and indirect discrimination. Additional areas of concern were indicated as including the persistence and lack of reliable information of entrenched harmful cultural norms and practices, the alarmingly high level of gender-based violence against women, with one in three women being subjected to physical or psychological violence by an intimate partner during the course of their lifetime, the limitations to access to education, health care and employment especially for the most marginalised groups of women. 


\section{Concluding Observations on the combined second and third periodic reports of the Cook Islands (Doc. NO $\mathrm{NEDAW} / \mathrm{c} / \mathrm{COK} / \mathrm{co} / 2-3,20 \mathrm{July}$ 2018)}

The CEDAW expressed appreciation for important legislative developments taken by the State Party, including the Family Protection and Support Act, the Harassment Act (which provides for protection against violence and abuse when there is no domestic relationship), the Employment Relations Act (which prohibits discrimination on the ground of maternity status), the Education Act (which provides for continued education for young women and girls following pregnancy), as well as the efforts to improve the policy framework, including through the adoption of the National Policy on Gender Equality and Empowerment of Women, and its Strategic Plan of Action 2011-2016. The CEDAW noted however with concern the lack of a comprehensive definition of discrimination against women, the inadequate financial and human resources devoted to the implementation of the national gender strategy, the persistence of discriminatory stereotypes in the State party, which subject women to multiple forms of discrimination, undermine their social status and may constitute root causes of gender-based violence, in particular domestic violence. Additional areas of concern included the lack of efforts to prevent exploitation of prostitution and the lack of exit programmes for women wishing to leave prostitution, women's low participation in political and public life, and the inadequate protection mechanisms for vulnerable women. Finally, the CEDAW also noted the lack of a gender perspective in policies or programmes on climate change, disaster response and disaster risk reduction and mentioned the need to take into deeper consideration the disproportionate impact of climate change, including with reference to climate induced disasters, on women and girls in the State party.

\section{Committee on the Rights of Persons with Disability (CRPD)}

\section{Concluding Observations on the initial Report of Nepal \\ (Doc. No CRPD/c/NPL/CO/1, 16 April 2018)}

The CRPD noted that, before the ratification of the Convention, Nepal had a number of laws in place aimed at protecting the rights of persons with disabilities, and expressed appreciation for the Country's efforts to bring that legislation in line with its obligations under the Convention. The CRPD was concerned that Nepal continued to adhere to the World Health Organization definition of disability, which is too focused on inherent personal or medical limitations and overlooks conditions arising from the environment. This may result in 
marginalization of persons with disabilities who have an indigenous background or are from rural areas. Therefore, the Committee recommended that Nepal adopt a more human rights focused definition of disability and strive to ensure equal access to services, especially for persons with disabilities facing multiple and intersectional forms of discrimination, particularly women and girls. The CRPD stressed the paramount importance of providing information to women with disabilities, since they might have a hindered access to rights. Furthermore, the Committee expressed its concern with regard to the absence of specific measures to support children with disabilities and to promote inclusive education. A further area of concern was represented by the lack or inadequate accessibility of persons with disabilities, which risks being amplified vis-à-vis persons with disabilities living in rural or remote mountainous areas. Thus, the CRPD encouraged Nepal to strengthen its monitoring capacity in order to improve its policy on accessibility. Finally, the CRPD underlined the necessity for Nepal to take steps towards ensuring equal access to education and job market for persons with disabilities.

\section{Committee on the Elimination of Racial Discrimination}

\section{Concluding Observations on the combined eighteenth to twentieth periodic reports of Jordan (Doc. NO $C E R D / C / J O R / 18-20,24$ December 2017)}

The Committee welcomed measures undertaken by Jordan, such as the adoption of a national strategy for women and a national human rights action plan. However, the CERD regretted that Jordan did not provide data on the ethnic composition of the population, as well as on the enjoyment of economic, social and cultural rights, contrary to what requested by the Committee in its previous observations. Therefore, it requested the State party to provide such data in the future. On another note, the CERD recommended Jordan to provide the National Centre for Human Rights with adequate resources to carry out its function and mandate. Furthermore, the CERD reiterated its previous concluding observations and recommended Jordan to enact comprehensive domestic legislation aimed at prohibiting direct and indirect racial discrimination, thus complying with the Convention. Further recommendations were related to the situation of persons of Palestinian origin, Syrian refugees and other minorities, such as Roma. The CERD expressed deep concern especially with regard to the practice of withdrawing nationality to persons of Palestinian origin and to providing access to services to Syrian refugees. Finally, the Committee recommended Jordan to take measures to protect migrant workers from exploitation. 


\section{Concluding Observations on the combined fourteenth to seventeenth periodic reports of China (including Hong Kong, China and Macao, China) (Doc. No CERD/c/cHN/co/14-17, 19 September 2018)}

Among the measures for which the CERD expressed appreciation were the plan for supporting the development of small ethnic groups and for tackling rural poverty and development, as well as achievements in reducing poverty. However, the Committee reiterated its concern that domestic legislation did not contain a definition of racial discrimination in line with the Convention and thus urged this to be brought in line within domestic legislation. Moreover, the CERD was concerned by the lack of comprehensive statistics and data on racial discrimination complaints and, to this end, recommended the State Party to carry out training programmes on anti-discrimination laws for government officials and to provide statistics on complaints. Similarly, it regretted the lack of information on tools available to victims of hate crimes. Regarding the latter, the CERD pointed out the necessity to combat racist hate speech, especially propagated by the media and recommended conducting training programmes for law enforcement officials, as well as a regular monitoring of racist hate crimes. Concerning development and eradication of poverty, the Committee the State's part commitment to a people-centred approach; however, it was concerned especially for the impact of poverty on women and ethnic minorities, as well as on migrant workers. Attention to gender dimension, rights of migrant workers and ethnic groups was a cross-cutting issues in the Committee's recommendations, particularly with regard to health and education. Moreover, the CERD welcomed the State's information that, by 2020, it will eliminate the distinction between agricultural and non-agricultural residence registration (hukou system), which had created several disparities. Finally, the CERD was concerned about the restrictions of movements imposed on Tibetans and recommended China to revise its regulations and practices.

\section{Concluding Observations on the combined eighteenth to twentieth periodic reports of Nepal (Doc. NO $\mathrm{CERD} / \mathrm{C} / \mathrm{NPL} / \mathrm{CO} / 17-23,29 \mathrm{May}$ 2018)}

The Committee welcomed Nepal's ratification or accession of a number of human rights treaties, such as the Optional Protocols to the Convention on the Rights of the Child on the involvement of children in armed conflict and on the sale of children, child prostitution and child pornography, the Optional Protocol to the Convention on the Elimination of All Forms of Discrimination against Women, the Indigenous and Tribal Peoples Convention, 1989 (No. 169) of the International Labour Organization (ILO) and the Convention on the Rights of Persons with Disabilities and its Optional Protocol. Moreover, it also 
commended Nepal for amending some of its legislation to comply with its human rights obligations. Nevertheless, the CERD expressed concern for the lack of prohibition of discrimination on national or ethnic origin, as well as of direct and indirect forms of discrimination. Moreover, it was also concerned about the lack of effectiveness of complaints against acts of racial discrimination and recommended Nepal to take measures in this regard. As for castebased discrimination, the CERD noted several practices of segregation and marginalization, especially in the areas of work and education and in relation to women. Thus, it recommended Nepal to monitor, investigate, prosecute and sanction such violence, as well to raise awareness on this topic. It also recommended Nepal to ensure that law enforcement officials are sufficiently training to identify such crimes. Further areas of concern flagged by the CERD related to indigenous people, migrants and asylum-seekers (with regard to the latter since Nepal did not have a formal asylum system in place, thus placing the principle of non-refoulement at risk).

\section{Concluding Observations on the combined ninth to eleventh periodic reports of Tajikistan (Doc. NO CERD/c/TJK/CO/9-11, 19 September 2017)}

The CERD welcomed the ratification of the Optional Protocol to the Convention on the Elimination of All Forms of Discrimination against Women and of the Convention on the Prevention and Punishment of the Crime of Genocide. Moreover, the Committee also welcomed State's efforts to improve its legislation aimed at protecting and promoting human rights. The CERD the steps undertaken by Nepal to collect data on ethnic composition; however, it remarked that such data were not accessible to the public. Although the Committee took note of Nepal's relevant legislation aimed at prohibiting racial discrimination, it reiterated its concerns that it may not be in line with the Convention, as the definition of racial discrimination was not as comprehensive as the one enshrined in the Convention and not all rights and freedoms foreseen in the latter were present in Nepal's domestic legislation. Further areas of concerns related to the equal access to public life for ethnic minorities, structural discrimination of Roma/Jughi and restrictions on the freedom of movement for asylum-seekers and refugees, the majority of whom originated from Afghanistan. With regard to stateless persons, the Committee welcomed the efforts undertaken by Nepal in relation to identification and registration and encouraged the State to continue with such measures. 


\section{Concluding Observations on the combined ninth to eighteen to twenty-first period reports of the United Arab Emirates (Doc. NOCERD/C/ARE/CO/18-21, 13 September 2017)}

The CERD accepted positively the legislative and policy measures taken by the State party to combat discrimination, especially on the grounds of race, religion and national origin. Moreover, it welcomed the ratification of international human rights instruments, namely the Convention on the Rights of Persons with Disabilities, the Convention against Torture and Other Cruel, Inhuman or Degrading Treatment or Punishment and the Optional Protocol to the Convention on the Rights of the Child on the sale of children, child prostitution and child pornography. However, the CERD also noted with concern that the prohibition of discrimination adopted at domestic level was not fully compliant with the Convention's definition and recommended the United Arab Emirates to enact legislation in line with the Country's commitments. The CERD, then, analysed the issue of access to justice. On the one hand, it noted the Country's efforts in educating workers on their legal rights, but on the other hand it voiced its concern regarding the treatment of foreign workers and their access to justice. More specifically on foreign workers, the CERD underlined its preoccupation for wage differentials between foreign employers from different regions. Moreover, it also pointed out the lack of regular monitoring and enforcement measures, as well as abusive working practices, such as long working hours. Other recommendations concerned the need for the United Arab States to collect regular statistics, which would allowed a better analysis.

\section{Concluding Observations on the combined tenth to eleventh period reports of Japan (Doc. NO CERD/C/JPN/CO/10-11, 26 September 2018)}

The CERD welcomed legislative and policy measures taken by Japan, such as those aimed at tackling human trafficking and discretionary hate speech and at promoting gender equality. At the same time, the Committee expressed concern since the State party had not implemented some of the recommendations previously received, for example those related to the adoption of a legislative framework containing a definition of discrimination in line with the Convention and at explicitly prohibiting racial discrimination. A further area of concern was identified in the delay in adopting a human rights commission bill. The CERD expressed appreciation for the measures undertaken by Japan to combat hate speech and hate crimes, especially following the adoption of legislation to this purpose. However, concerns remained regarding the limited scope of it, being limited to hate speech against persons 'lawfully residing in Japan'. Moreover, the CERD found the following areas to be problematic and in 
need of further engagement by Japan, i.e. hate speech through the media and internet and lack of investigations and accountability for hate crimes. The CERD recommended Japan to tackle discrimination against the Ainu, Burakumin and Ryukyu/Okinawa people, especially with regard to access to education, employment and other services. As far as women are concerned, the Committee remained concerned at reports of intersecting forms of discrimination against women with a foreign, indigenous and minority background, who were often victims of discrimination based on compounded factors, namely gender, national origin and ethnicity. Therefore, the CERD recommended Japan to dedicate adequate attention to women in this kind of situations, including by taking immediate measures aimed at registering violations against them.

\section{Committee on Economic, Social and Cultural Rights (CESCR)}

\section{Concluding Observations on the initial report of Bangladesh (Doc. NOE E/C.12/BGD/CO/1, 18 April 2018)}

The CESCR acknowledged the progress made by Bangladesh since its accession to the Covenant, including towards poverty reduction and in advancing gender equality. However, the Committee expressed preoccupation for the fact that the rights enshrined in the Covenant had not been fully incorporated at domestic level and especially that they were not justiciable. As for specific issues, the CESCR focused its attention on several issues, ranging from climate change to work and education. With regard to climate change, the Committee recommended Bangladesh to adopt strategies and action to tackle the adverse effect of climate change on the enjoyment of economic, social and cultural rights. The CESCR then made several recommendations to Bangladesh aimed at improving the enjoyment of rights of economic, social and cultural rights of the most vulnerable parts of the society, such as indigenous people, Rohingya refugees and migrant workers. Then, it looked at issues which have a direct effect on the enjoyment of the aforementioned rights. In relation to this, the CESCR noted with concern the pervasiveness of corruption and its impact and recommended Bangladesh to take concrete steps to ensure transparency in public affairs. Another area identified by the CESCR regarded the right to work, since the majority of the labour force was working in the informal economy, thus without any social and labour protection. In addition, fair conditions of work were not always guaranteed, especially minimum wage. Finally, the CESCR made recommendations with regard to the need to strengthen measures against sexual and gender-based violence, to protect children from 
exploitation and to ensure access to education and basic services such as water and sanitation.

\section{Concluding Observations on the initial report of the Republic of Korea (Doc. NoE E / c.12/KOR/co/4, 19 October 2017)}

The CESCR underlined welcomed measures taken by the Republic of Korea aimed at promoting economic, cultural and social rights. However, it expressed preoccupation since the legislative framework allowed only a restricted scope to the operation of the Covenant, therefore limiting its implementation in practice and availability of effective remedies. Further, the CESCR expressed preoccupation with regard to the interaction of business and human rights, noting the absence of a legal obligation, for companies, to exercise human rights due diligence. It therefore recommended the establishment of such an obligation, as well as to act upon allegation of violations of human rights resulting from the activities of Korean companies. Several recommendations were related to the area of labour rights, primarily with the aim to ensure that workers' rights, including migrant workers, were adequately promoted. Recommendations were thus focused on issues such as adequate remuneration, gender pay gap, right to strike, labour and social security and trade unions. In addition, the CESCR looked also at obstacles to the enjoyment of economic, social and cultural rights for vulnerable segment of the population, such children and elderlies. As for the former, recommendations were mainly related to access to quality education as well as to tackling abuse and exploitation. Finally, the CESCR made a number of recommendations related to the right to water, housing and access to health, noting, with regard to the latter, the importance of ensuring also adequate care for mental health.

\section{Committee on the Rights of the Child (CRC)}

\section{Concluding Observations on the combined fifth and sixth periodic reports of Sri Lanka (Doc. No CRC/C.12/LKA/CO/5-6, 2 March 2018)}

The CRC noted the progress achieved by Sri Lanka in various areas related to the implementation of the Convention, including the legislative and policy measures adopted to this extent, particularly the National Plan of Action for Children and the plan of action on social protection for children. At the same time, the Committee reminded the State party of the indivisibility and interdependence of all the rights enshrined in the Convention and drew the State's attention to the importance of implementing recommendations related to urgent measures to be taken, especially in relation to violence and 
corporal punishment, sexual and economic exploitation, child labour and juvenile justice. Furthermore, the CRC recommended Sri Lanka a series of general measures to ensure the full implementation of the Convention, such as: transposition of the convention provisions into national legislation, in order to ensure that all principles and rights provided therein can be fully applied by judicial and administrative authorities, necessity to bring national legislation in line with the Convention, need to increase efforts to implement the National Plan for Action for Children and to allocate adequate resources to this extent and ensure that the National Child Protection Authority is independent and fully able to exercise its function. In addition, the CRC recommended the State party to undertake a series of measures aimed at increasing awareness with regard to discrimination and recognition of children's rights. To this end, the Committee urged Sri Lanka to incorporate the principle of non-discrimination into domestic legislation and ensure that the latter is in full compliance with the Convention. Finally, other recommendations were directed to tackling sexual exploitation and abuse, gender-based violence, child labour, and to ensure children's well-being in particular in relation to mental health, family environment and education.

\section{Concluding Observations on the combined third to fifth periodic reports of Tajikistan (Doc. No $c R c / c / T J K / c O / 3-5,29$ September 2017)}

The CRC welcomed the progress achieved by Tajikistan in various areas, including the ratification of or accession to international instruments. The CRC noted with appreciation the measures undertaken to implement the Convention, in particular the Children's Rights Act and the creation of the post of Commissioner for Children's Rights. However, the Committee reminded Tajikistan of the indivisibility and interdependence of all the rights enshrined in the Convention and underlined the importance of implementing the recommendations put forward to the State party. In particular, recommendations related to corporal punishment, family environment, children with disabilities, health services, nutrition and juvenile justice. Therefore, the CRC encouraged Tajikistan to adopt a comprehensive national policy on children that encompasses all areas covered by the Convention and develop a strategy for its application. In addition, the CRC urged the State party to allocate adequate human and financial resources to departments working on the protection of children's rights in order to ensure the implementation of the Convention in a cross-sectoral manner. Furthermore, the Committee remained concerned that children under 17 years old can still be married; to this end, it urged Tajikistan to eliminate any exception to the minimum age of marriage and to take measures to eliminate child marriages. Other areas underlined by the CRC related to 
non-discrimination, family environment, nutrition, mental health, HIV, standard of living, education and children belonging to minority groups.

\section{Committee on the Protection of Migrant Workers (CMW)}

\section{Concluding Observations on the initial report of Indonesia (Doc. NOCMW/C/IDN/CO/1, 19 October 2017)}

The Committee welcomed the submission of the initial report of Indonesia as well as the additional information provided by the Indonesian delegation. It further took the occasion to appreciate the open and constructive dialogue held with the State party, although it noted with regret that sometimes information was too general or incomplete, especially with regard to the practical implementation of the Convention. The CMW recognised that Indonesia was becoming a country of transit and destination for migrant workers and therefore needed to boost its efforts in protecting them. As for positive aspects, the CMW welcomed the ratification of or accession to a series of international instruments, such as the International Labour Organization Maritime Labour Convention and the Protocol to prevent and suppress trafficking in persons. It further noted with appreciation that Indonesia had adopted legislative and policy measures aimed at improving the rights of migrant workers, such as the establishment of the Task Force on Migrant Workers. However, the CMW was concerned about the lack of a comprehensive legislation on migration and the insufficient measures undertaken to ensure that the State's legislation was in compliance with the Convention. The CMw recommended Indonesia to develop educational and training programmes on the right of migrant workers and to take further steps to ensure that they have information on their rights under the Convention. Other areas with regard to which the CMW made recommendations were related to non-discrimination, right to an effective remedy, border management, labour exploitation, social security, children in situations of international migration and migrant domestic workers. 
PART 5

\section{Book Reviews}


